\title{
First look at Pluto: Live coverage of the historic fly-by
}

Nature reports from New Horizons mission headquarters.

\section{July 2015}

On 14 July, NASA's New Horizons spacecraft will get the best view yet of Pluto, passing roughly 12,500 kilometres from the dwarf planet at the fringes of the Solar System.

Join Nature reporter Alexandra Witze and a team of Pluto experts for live reporting and commentary on 14 July, beginning at 7 a.m. Eastern daylight time. We'll be taking questions on our live blog; you can submit them ahead of time by commenting on this article, or by posting your questions on Twitter using the hashtag \#AskNature.

And if you'd like to brush up on all things Pluto before the big day, check out our special report at www.nature.com/pluto.

\section{Meet our panel}

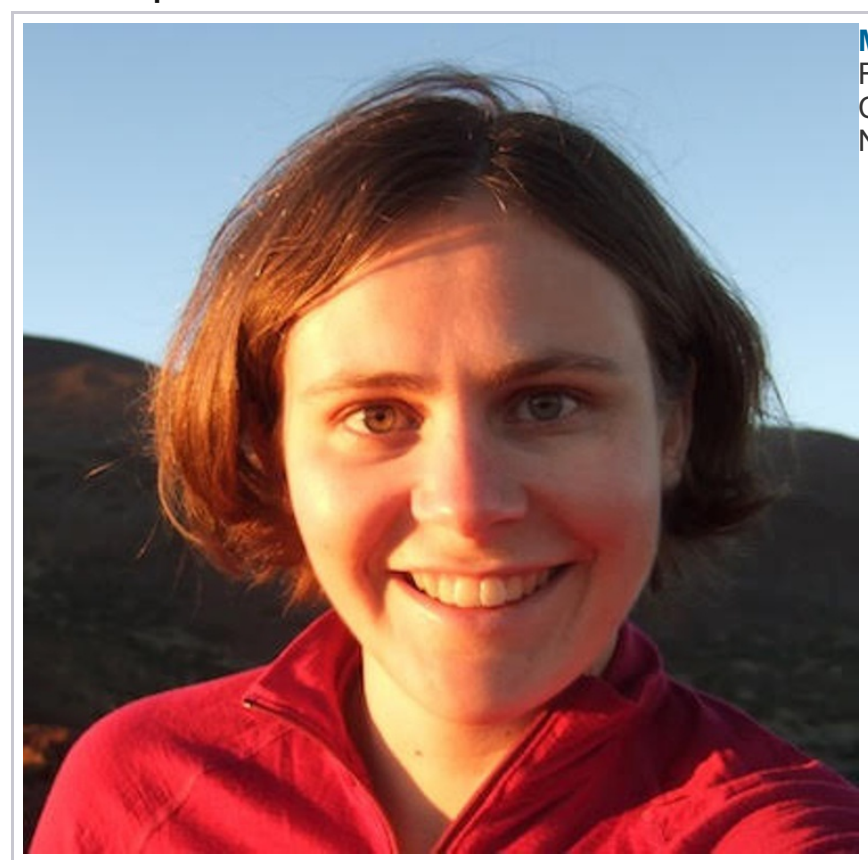

Michele Bannister is a planetary astronomer at the National Research Council of Canada's Herzberg institute in Victoria, British Columbia. She specializes in hunting for small icy worlds beyond Neptune. 


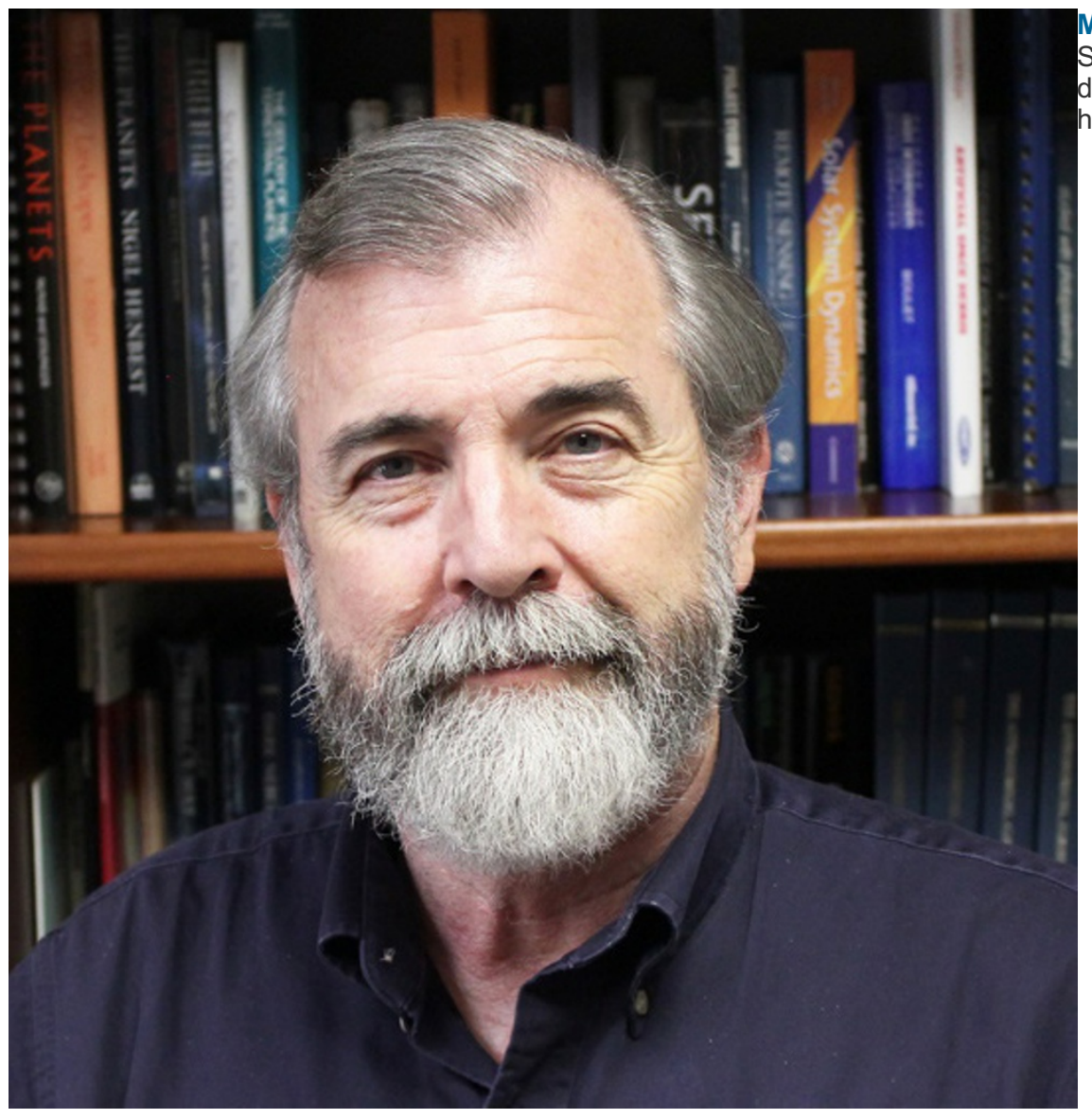

Mark Sykes is the director of the Planetary Science Institute in Tucson, Arizona. He once designed a Pluto orbiter mission that would have been powered by a uranium reactor. 


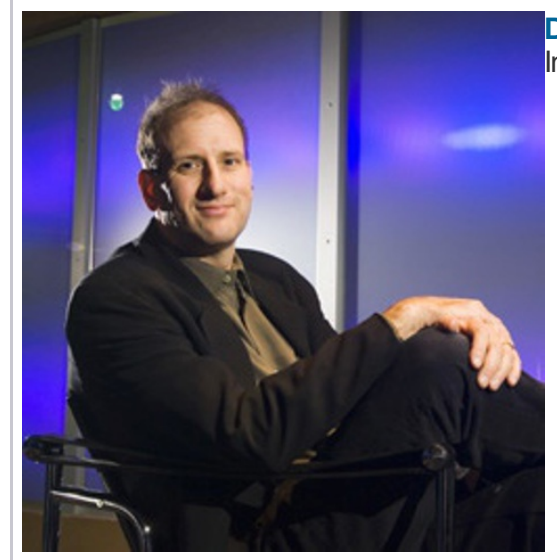

David Grinspoon is a multidisciplinary researcher and writer at the Planetary Science institute. He held the first chair in astrobiology at the Library of Congress.

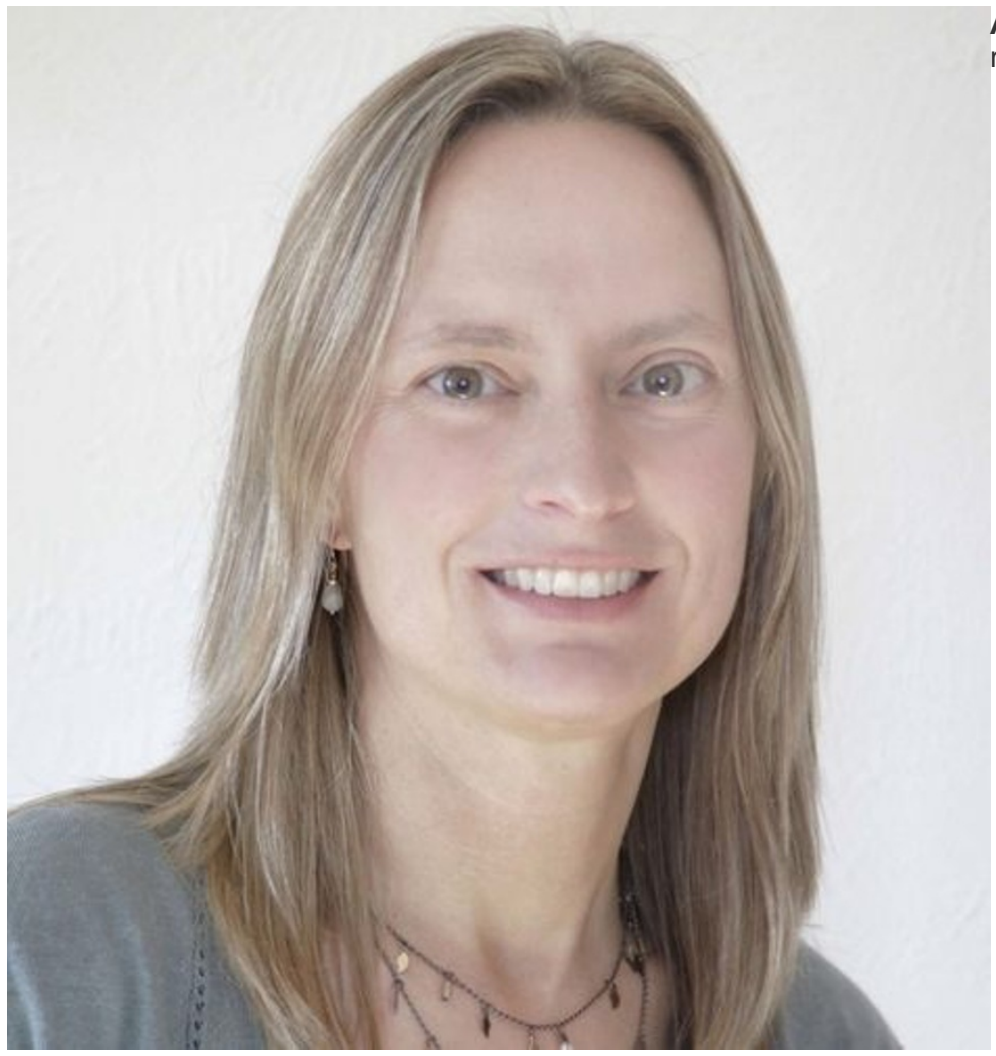

Alexandra Witze is an Earth and planetary sciences reporter for Nature.

Nature | doi:10.1038/nature.2015.17905 